\title{
Monetizing French Distance Education: A Field Enquiry on Higher Education Value(s)
}

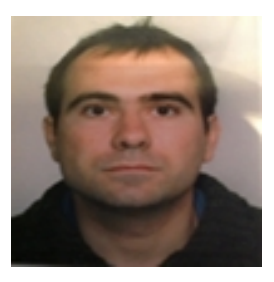

Olivier Marty

Cnam, France

\section{Abstract}

A field enquiry in French distance education allows us to analyze the evolution of a specific institution towards new public management: Parallel to a trend of free courseware and open education, there is a paradoxical reality of distance education monetization. Whereas history shows how traditional French education is a state controlled public good, a new policy is changing the organization's culture towards a commercial and industrial activity. From inside the institution, we describe the cultural changes, with its human resources, accounting, and marketing dimensions. We relate debates about the institution's business model within the economy of knowledge selling either services or contents, focusing on the learner's experience. Lastly, we analyze the notion of value underlying this monetization of a distance education institution: both the computing of a specific training's value and the shared values of the workers binding up their collective identity.

Keywords: Money; distance education; France; marketing; value 


\section{Introduction: From Participatory Observation to Education Sciences Analysis}

\section{Collection of Data}

Since 2011 I have been conducting a participatory observation within a French national distance education institution, occupying training engineering and management functions within the organization. My main focus of analysis is education management, since it is the research axis of the education sciences laboratory I belong to (Cnam, CRF, Axis 4).

Attending to the organization's daily life, with a declared research goal, I have collected empirical raw material, archived online ${ }^{1}$. I want now to take some distance to rethink my ethnographical data in order to place it within the long run evolution of French national distance education.

During this ethnographic study, which could become an exploratory work for a larger quantitative enquiry, I have observed a deep change in the organization's culture: recruiting private sector executives to replace civil servants and precisely accounting for every single resource and investment in order to be profitable on the e-learning market. I want to describe and analyze precisely this monetization of a public institution, conducted in an atmosphere of possible privatization. I will try to show that this mutation is deeply changing education's value: both the estimated value of a particular training course (how much is it worth on the market?) and the workers' values within the institution (what do they value in their educational work?).

\section{Review of Literature}

My article is framed by fundamental research on distance education (Moore, 2012) as well as by French distance education history. I will, for example, discuss the dilemma between selling either method or pedagogy, which has a correspondence with Moore's transactional model: Pedagogy is related to communication whereas method is in relation to course structure. Moore, in his recently reedited handbook, collaborates with Otto Peters, who is fundamental to understanding the process of industrialization of education and mega universities. These works had a French reception by J acques Perriault - former researcher within the institution studied - and nowadays Pierre Moeglin and the scientific review Distances and Mediations of Knowledge.

At the Conservatory, where I conduct my research, I am indebted to J ean-Marie Barbier's (2009) work on education activities. I use social sciences methods as taught at École Normale Supérieure where I have been trained by Florence Weber (2008), influenced by the North American author Erwin Goffman. Methods of specialized

\footnotetext{
${ }^{1}$ http://educations.voila.net
} 
ethnography within higher education organizations are detailed by Mercer (2007) and Trowler (2012).

The history of the French education system is a field of research covered by Prost (2007) and Lescure (2010) for the part concerning adult education. The international question of commodification of education has been analyzed and criticized by Shumar (1997, 2008).

Finally, the measure of value within an organization has been discussed by Vatin (2008), with an influence from John Dewey (1997). The question of the values of a community, personified by leaders, is the central question of my $\mathrm{PhD}$, defended at the University of Western Paris in 2011 (author's online publication).

\section{Distance Education History within the French State System of} Education

\section{Education as a Public Good, Provided by the French Central State}

Since the $18^{\text {th }}$ century, French education has been state controlled: First engineering schools like Ecole des Ponts et Chaussées (1747) or Ecoles des Mines (1783) were created by government in order to provide trained workers for key functions of the administration, such as construction of bridges, roads, and organization of mines. Therefore, medieval universities (La Sorbonne university, Toulouse University, etc.), still partly supervised by Catholic Church powers, were in competition with these public state schools. A new system of production of the elites was created, reinforced by the French Revolution (1789-1799) and Napoleonian Imperial University.

Since then, higher education has been organized by the French state, giving the right to universities and public schools to deliver diplomas. In France, higher education has been and still is a state concern. In 1838 was created the Ministère de l'instruction publique, rebaptised in 1932 Ministère de l'éducation nationale and currently named the Ministère de l'enseignement supérieur et de la recherche, dedicated to higher education.

Private organizations entered this field of higher education in the 19th century: École supérieure de commerce de Paris, the first private business school, was created in 1819 and other provincial initiatives followed. Today these schools are under state control since their diplomas are evaluated by the Ministry of higher education and research. 
As a result of this 250 year history, education has been considered a public good of general interest, provided by state institutions and controlled by the French government. Money is not the main value: Knowledge is the central item and it relies on meritocracy, that is to say the best position given to the best learner. State grants are provided to students coming from low income families and access to training is free. The main selection is not money-based but made through competition: The difficulty of a “Grande École's “concours d'entrée” is what makes it and its students valuable.

An ideology of equity between all French young students is well spread in the education system: The most prestigious curricula are based on mathematics, where performances are said to be less sensitive to family background than for French language subjects. Politically, most teachers are on the left wing and French sociologists (like Bourdieu, 1990) are known for their criticism of the system's imperfection (i.e., elites' social reproduction).

However, with the development of lifelong learning (a European policy), adult training and the influence of the Anglo-American model of private education in Europe, France may have to change this state tradition. Indeed, many student exchanges (like the Erasmus program in Europe) confront the public service with private curricula from other countries. Research activity necessitates fund raising and this is part of a process of privatization of science (Feyerabend, 2010) and education. In France, a 1971 law for permanent education fostered company training of workers. A new market for adult training was born, where universities, schools, and specialized organisms (independent or "université d'entreprise") are now competing. This competition soared with a technological evolution during the 2000s due to the Internet and e-learning development.

This is the educational environment of distance education, state public service created in 1939 to provide instruction to French young learners in parts of France occupied by Germans at the beginning of World War 2. I will try to show that, since its creation, this public service has been a rather innovative institution and how it is now anticipating a possible shift towards a privatization of education.

\section{Distance Education: From a Public Service to a Profitable Institution}

In France distance education is represented by a public institution created in 1939, by the occupied State of France. It has grown after the war into a public service, reaching the status of an academy (education administrative subdivision of the French territory) in 1986. First positioned in Paris, it moved to Futuroscope (central region) in the 1990's and counts eight sites all over French territory. It is a public administration under the control of both the Ministère de l'éducation nationale and the Ministère de l'enseignement supérieur et de la recherche. It provides learners with a complete curriculum, from primary school to master degrees. 
All along its development, the institution has grown into an industrial producer of knowledge, sending lectures and education material to hundreds of thousands of learners (200,000 in 2011). This industrialization, characteristic of a massive education institution, was associated with the experimentation of all new pedagogy technologies: Lectures sent by post were soon accompanied by telephone contact, television, Minitel and finally the Internet with web sites, email, forum, chat, virtual classes, and so on. The institution was a tool to experiment with the massive use in French education of new technologies.

However, whereas primary and secondary education (which is compulsory in France, until the age of 16) are considered as a public service, with a legitimacy to be state funded and free for all citizens, higher education is reconsidering its position. Indeed, the French ministry for higher education and research asks the institution to be selfsufficient as to what concerns higher education and adult learning.

Therefore, the institution has to rethink its business model: The value of each training course has to be reconsidered to measure whether it is profitable or not. Every training course is now competing in a distance learning market where there are many universities and schools, as well as private companies, investing in e-learning tools like learning management systems. It is in this context that we conducted our ethnographical study: The organization is under pressure and has to reinvent its business model. I will now describe this evolution from inside, with the change of habits, traditions, and new values imposed on workers.

\section{Institution's Transformation: Towards an Industrial Culture}

\section{Changing Human Resources}

Traditionally, the distance learning institution's higher education service recruits state teachers in order to manage its training courses and programs. They come from high schools or universities and are recruited for a job that is slightly different from what they are used to: They focus on the administrative part and don't have to teach any longer. The job is about recruiting and making contracts for authors and tutors, conceiving new curricula and elaborating partnership with publishers or universities. It is both an activity of management and training engineering. The workers we studied have to harmonize different departments: a production department in charge of printing and sending lectures, or preparing learning websites; an administration department in charge of admission, collecting and having tests corrected, sending the final training certification (signed by the manager/ engineer).

However the mode of recruitment changed when we conducted our participatory observation: With the rise of new public management (NPM), a new direction was 
established to give priority to workers coming from the private sector (having worked with a publisher, an adult training company, etc.) or trained in private business schools. Being a "pedagogue" with strong in-classroom experience was no longer the main criteria to be selected. Civil-servants are nowadays in competition with private workers and everyday life has changed.

At a higher level, I had informal interviews with directors who were recruited in order to determine and conduct the organization's strategy. Their very title says a lot about the new public management they represent: They are called "business unit directors", and their services are defined by the market segment they target. Most of them are outsiders, having professional experience in private organizations not necessarily linked with education. They represent the new generation, wearing suits and ties, talking about clients and money.

\section{Changing Workers' Habits}

I first observed confusion in the vocabulary used to designate the audience targeted by the institution. Whereas former employees use the word "usager" (which is the French word for any user of a public service), the new generation more often talks about "clients". The ideology of public service and common good is therefore replaced by the notion of private interest and the transaction of money opening rights to the consumer. However a compromise is found around the notion of "learner" ("apprenant"), designating neither a student nor a pupil but an adult engaged in specific training. This term refers to the institution's sector of activity and not its mode of operating (public/ private activity).

Another difference appears in the way people are dressed: Whereas the old generation of teachers have a casual style, the newcomers more easily come to work with a formal costume and a tie. The notion of time tends to be stricter: Employees' schedules are controlled by a time-machine (they have to badge in and out of the institution) in order to measure how much time they spend within this industry of knowledge.

And here comes the most important change: This focus on work measure is stressed by the top management. A few management controllers were hired in order to set up a tool to measure the activity. After having audited all sites and departments, they built up an Excel spreadsheet computing all the costs of specific training. Whereas the most experienced employees had the habit of creating new training courses without knowing in detail how much it would cost or whether it would be profitable, they now have to estimate precisely the amount of money they invest and the expected return on investment.

The employees have to fill in many costs within the Excel document: how many days spent conceiving and then coordinating the pedagogical device; how many pages of lectures brought to authors; how many pages to design and to publish a website by the production department; how much time spent animating the forum and website; how 
many hand-ins to be corrected by the tutors; how many days of presence in a classroom for hybrid training combining distance and presence. All these costs are summed up and compared to the prevision of learners and the estimated price of the training (fixed by a specific worker in charge of analyzing all of the institution's prices). Then the Excel tool gives a financial analysis, with margin, benefits, and cash flows. Thus, all workers are fostered to discover this accounting dimension and see reality through this economic focus.

This is a major cultural change since none of them had this habit of accounting - and a few among the eldest had difficulties with the Excel computer tool. This reform led to a great deal of trouble among the workers (at least the ones of the older generation, judging the tool as impossible to handle given the complexity of their training projects). It took a few months to accept the use of this tool and it is still not well considered by all.

Another tool recently implemented by top management is a validation of all new projects through a process entitled "product's life cycle". Like in the industrial sector, all the training courses are considered as products, which are born, developed, and finally suppressed whenever they are no longer profitable enough. Training engineers therefore have to fill in this document, including many business considerations they had no habit of: market, commercial target (quantitative data and qualitative comments about this target), general description of the pedagogical dimension of the product (is it innovative? what are the services included?), planning of implementation, income hypothesis, and so on. Here again this marketing process, illustrating new public management, had a cold reception by former teachers. They saw an invasion of economics into their craft of pedagogy.

The cultural change just described is summed up by a current controversy within the institution. It is indeed an administrative public institution but rumors say that it may be turned into an industrial and commercial public institution. This change of legal status would be a turning point indicating a clear change in the organization's culture: Private sector habits and monetization would be the official nature of the institution. Unions and old employees are criticizing this possible change of status, arguing it would betray the spirit of French public education.

After this glimpse of everyday life micro evolution, let's consider how the institution is rethinking its business model. If it is now widely admitted that training involves money, there is not yet a consensus on what is to be sold. 


\section{Selling What to Whom? About Commodification of Education}

\section{Method versus Pedagogy}

Commodification of education in America has been described by Shumar $(1997,2008)$. In our European case we saw that it implied a few business tools to estimate the economic value of a specific training course in order to be profitable on the market. For both there is common evidence: Education is a product that can be sold.

At the institution I studied, however, there is still a debate about what is to be sold. In an interview, the general director of training declared that content was no longer the core of the institution's business model. Delivering a document (either paper or online), mere reading material or a video, is not the main added value of the training. It is the job of publishers to edit such content and sell it in the market. What I would call "method"2, that is to say courses' content, is what is traditionally seen by the consumer as the materialization of knowledge. Method is the result of the learning process, what has been learnt. However, the general director of training puts forward another item as more important: pedagogy.

Pedagogy 3 is a set of services provided by teachers to the learner. They orientate before any engagement in a curriculum (by phone), they help in case of difficulties in the course (through an online forum), they correct mistakes (on the hand-ins), they recognize the learning process (through marks and a certificate delivered by the institution), they give pieces of advice about future orientation (for any other training).

This economy of service that would replace the industrial production of content, according to the training general director, is however not clearly defined. There are debates about how it should be sold: free content and extra services bought one by one by the learner? Content plus services to be paid all at once? There is, in both cases, a challenge to think of economy of knowledge independently from these two dimensions of a teacher's craft: economy of service (pedagogy) and economy of production (method).

This strategic uncertainty may be due to contenders such as $\mathrm{MOOC}^{4}$ who are giving away much of their content and services, both method and pedagogy. Business models in distance education are therefore contested by universities and private institutions distributing their knowledge on the Internet. Decades old institutions have to reinvent what they sell and how they sell it to be competitive on the Internet market.

\footnotetext{
${ }^{2}$ From Ancien Greek mathein (to learn) and hodos (path): the mental path that will follow the learner, the sum of all that he will have conceived at the end of his training.

${ }^{3}$ From Ancient Greek paideia (child) and gogein (to lead): it refers to a notion of accompaniment.

${ }^{4}$ Massive online open courses
} 


\section{Learner's Experience}

Another controversy is about the learner's experience. Influenced by experiential marketing, attention is paid to what the learner will feel and live during his/ her training. A training course (or formation) is different from a mere piece of information since it is bigger (it is a complex set of information pieces) and goes deeper in the learner's mind. Learning a piece of information is an everyday process in order to solve common problems. But learning a complex set of information devices (going through a formation) is a much more important mental activity: It takes time, the learner tends to identify himself/ herself with the knowledge acquired, and he/ she will remember it for a longer period of time.

Therefore attention is paid to this learning experience. To amplify identification, a service of socialization has been set up. Since the experience of learning is stronger within a community, the institution set up a network tool supervised by a community manager. Learners can exchange tips and tricks about the course. They feel part of a learning team and there is both cooperation and competition. They help each other and they compete to outwit each other. There is solidarity in case of difficulty and honor amplifies the results of each and every individual learner. This service is provided for free up to now and the institution is thinking about an independent price from the training: Here again the business model is under construction.

Last, an alumni community is strengthened by a marketing tool. The institution invested in a specific website collecting learners' success stories. Testimonials from students having a double career as athlete or artist are highlighted with many images and positive comments. For example, a French surfing champion is interviewed since he did all his high school with the distance education institution, having therefore the possibility to study at hot surfing spots. Another example is a family who decided to sail all around the world, the children attending distant classes with the institution. A community manager deals with the website's forum, answering questions and orientating debates about the institution. Such marketing of training makes the learner's community more united around a few 'stars', leaders to follow. But it also allows the institution to convert prospects into clients. Indeed, the institution's online catalogue is directly linked to this website. The institution is therefore selling dreams, associating itself with rather innovative ways of life and learning experiences.

\section{The Professional Education Market}

Selling training courses, whether it is a combination of method and pedagogy or a new learning experience, is not natural in France. I showed earlier that French national history led to thinking that education was a public good by nature. However, with adult training development and lifelong learning, France's legislation changed. The 1971 law about permanent education created a new market: professional training financed by a company's human resources department (HR). 
This new market has been targeted by specific training organisms, but also by universities and public schools, adding new training programs to their portfolio. The institution we studied created a specific department dedicated to this professional market. This department, linked both with the commercial department and the training department, is highly representative of the commodification of education. Indeed, its main activity is to sell training to professional organizations. It is placed near the headquarters and represents modernity within the institution. Whereas most activities are scattered across eight different sites in France, this one is at the heart of the institution.

I therefore observed an institution moving from an administrative culture delivering a public good to an industrial culture selling profitable training on the market. Even if what is to be sold is not yet clearly defined, a tendency of monetization appears. Let's see what the consequences of this new strategy are. We will focus on the very notion of value and its estimation, underlying the question of money.

\section{A Question of Value(s)}

\section{Value of Training}

I showed how selling specific training implied its evaluation. Within the institution, this is made with particular software that sums up all costs and benefits and makes automatically a financial analysis (margin, profitability, etc.). It is a financial approach to value: All future costs and benefits are summed up and actualized at the present moment, in order to take a decision about whether to invest or not. Monetization implies that all training programs' value can be computed with numbers, quantified and estimated throughout time. This was hard to admit for most teachers but the shift in the organization's culture and employee turnover makes it a common reality for any new worker.

I want now to add a field-based complement to this financial analysis of value. Indeed, discounting coming gains and losses to estimate present value is future-oriented and does not take into account past experience. French teachers within this institution regularly say that school and training courses are here for values transmission. That is to say that a learner going through specific training will be changed deeply, so deeply that what he or she will consider as valuable will be different.

When a client buys training, he/ she discounts future gains (value of this training on the labor market for example) and losses (how much it costs, including opportunity cost, that is to say what he/ she could do instead of this training) in order to determine if the

price of the training is in tune with his/her personal estimation of its value. And when 
the distance education institution proposes a price for the training, it takes into account what the client would be ready to pay.

But what is missed in this value estimation is the learner's change of values throughout the training. For example, having done a training program in management, he/ she will be even more attracted by management than before and value therefore everything that deals with management. $\mathrm{He} /$ she will probably become a manager and will therefore retrospectively over-value his/her training in management. Generalizing this idea, training retrospectively increases its own value by itself: Since it implies a new valuation in the trainee's mind, it tends to legitimate itself.

The distance education institution I studied had the intuition of this estimation of value taking into account past experiences, and especially previous training courses. Indeed, a business unit manager wanted to implement a client hooking system: giving free training would hook a learner. Indeed, free training is a way to softly discover the institution and reduce the cost of uncertainty. But it is also a way to get addicted since a first training course leads to self-valuation of other training in the same field. It is an experience that values itself since it changes the learner's vision of the world.

However, if there is a quantification of future value of any training through the accounting tool, past-oriented valuation of a training device is still a qualitative approach within the institution I studied. There is monetization of the first one, not yet of the second one.

Let's move back to a broader analysis of the question of value within the institution. We saw how French distance education was embedded within a national history of state education. In the same way, the question of a specific training course's value and its monetization is embedded within the institution's values, that is to say the values of the educators' community.

\section{Values of an Educative Community}

I tried to show throughout this study how the worker's habits changed: new public management, money-based evaluation of training, new way of dressing and talking about learners, performance-driven organization through marketing tools and computer work, and so on. From one generation of training engineers to another, the values of the educators' community changed as I described it.

This quick evolution of the distance education institution (in about 3 years) draws a specific trajectory. It started as a public service of distance education, knowledge oriented, and moved to an almost private organization, money-driven. This quick evolution bound the group together: team-building based on a common trajectory had effects that appeared strongly when talking to the different workers. A solid collective identity around a mix of old and new values appeared, so much that there is even a 
specific word designating a member of this institution. This word is based on the name of the institution and makes any worker feel part of a well-integrated group.

How to describe this identity based on an institution's trajectory? When the new general director was appointed, he distributed a strategic document planning the institution's future. A new top management team was recruited and they spread this strategic plan. Middle management represented by training engineers had therefore common dreams about the future: where to go together. It was about money-based institutional and professional work. They then shared hard times together: difficult reforms of an administrative structure, repetitive changing of colleagues and managers, and so on. These strong experiences bound the group together in the difficulties endured. And finally, when looking back over one's shoulder, all of the workers have these shared experiences as common references supporting the collective identity. They value the times they shared together and their common history separating them from most of the traditional French education institutions.

Moreover I observed a process of hero-making. Indeed, in hard times, a few workers personifying the institution's values appeared: either top managers recruited to sell goods were admired for their revolutionary vision in tune with the general director's strategic orientation; or old generation training managers, representing traditional education values, were praised for their efforts to adapt to the new situation. The group under pressure built a common imagination with heroes personifying values and accomplishing acts relevant to the new strategy.

As a result, most of the workers agree on a good atmosphere within the institution. Even leavers talk about their attachment to the institution. It is a sign that a fast trajectory leads to a highly integrated community with strong shared values.

\section{Conclusion: Retrospective and Prospective}

To sum up, the fieldwork in a major French distance education institution led to an education sciences analysis. I tried to show how state controlled education in France gave birth to a specific distance education organization about 70 years ago. This institution recently moved towards new public management, with a high turnover and many mutations in daily work in order to optimize production. Among these changes, I focused on monetization of training. This led to a description of training marketing, training accounting, and current debates about the institution's business model. If there is still hesitation about whether to sell courses' content or pedagogy services, it is agreed that the learner's experience of the training is central.

Last, I tried to analyze the notion of value underlying this monetization process: both the computation of any training program's value (future or past oriented) and the 
change in the institution's values. Indeed, this rapid evolution of the institution bound the group together around a few important experiences and valued corporate heroes.

A prospective could be the institution's stabilization now that it has been so rapidly and deeply moved. Such a possible stabilization in its new identity (selling training defined as private goods to be monetized on the market) could lead to a slower development in the same direction, supported by collective memory of this unique trajectory I described.

More generally and from a long term perspective, we can situate this monetization of French distance education within two contradictory trends of, on the one hand, free open online education and, on the other hand, privatization of teaching - implying commodification by a common measure of knowledge's value. By focusing on a microscopic case, we can describe precisely a macroscopic shift in education, shaping tomorrow's learning landscape. 


\section{References}

Babier, J . M., Bourgeois, E., Chapelle, G., \&Ruano Borbalan, J . C. (2009). Encyclopédie de la formation. PUF-Demos.

Dewey, J . (1997). Experience and education. Kindle Edition.

Feyerabend, P. (2010). Against method. Verso.

Lescure, E. (2010). Les métiers dela formation: Approches sociologiques. PUR.

Mercer, J . (2007). The challenges of insider research in educational institutions: Wielding a double-edged sword and resolving delicate dilemmas. Oxford Review of Education, 33, 1-17.

Moore, M. G. (2012). Handbook of distance education ( $2^{\text {nd }}$ ed.). Mahwah, NewJ ersey, London: Lawrence Erlabum Associates.

Prost, A. (2007). Regards historiques sur l'éducation en France, XIX-XXèmes siècles. Belin, Histoire de l'éducation.

Shumar, W. (1997). College for sale: A critique of the commodification of higher education. Falmer Press.

Shumar, W., \& Canaan, J . (2008). Structure and agency in the neoliberal university. Routledge/ Falmer.

Trowler, P. (2012). Doing insider research in universities. Amazon Kindle edition.

Vatin, F. (2008). Letravail et ses valeurs. Albin Michel.

Weber, F. (2008). Manuel de l'ethnographe. PUF.

\section{Athabasca University $\mathbf{Z}$}

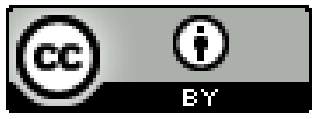

